\title{
Role of angiotensin II type 1 receptor in cerebral aneurysm formation in rats
}

\author{
TOMOHIRO AOKI $^{1}$, MASAKI NISHIMURA ${ }^{1}$, HIROHARU KATAOKA ${ }^{1}$, RYOTA ISHIBASHI ${ }^{1}$, \\ TAKASHI MIYAKE ${ }^{2}$, YASUSHI TAKAGI $^{1}$, RYUICHI MORISHITA $^{2}$ and NOBUO HASHIMOTO ${ }^{1}$ \\ ${ }^{1}$ Department of Neurosurgery, Kyoto University, Graduate School of Medicine, 54 Kawaharacho, \\ Shogoin, Sakyo-ku, Kyoto 606-8507; ${ }^{2}$ Department of Clinical Gene Therapy, Osaka University, \\ Graduate School of Medicine, 2-2 Yamadaoka, Suita City, Osaka 565-0871, Japan
}

Received September 11, 2008; Accepted November 24, 2008

DOI: 10.3892/ijmm_00000239

\begin{abstract}
Cerebral aneurysm (CA) causes catastrophic subarachnoid hemorrhage which is characterized by a high mortality and morbidity rate. $\mathrm{CA}$ is a common disease worldwide but to date there is no medical treatment against unruptured CAs. Thus, it is important to study the mechanisms of CA formation. Our previous report demonstrated that chronic inflammatory response in cerebral arterial bifurcation by hemodynamic stress deteriorated arterial walls and formed CA. Therefore, drugs with anti-inflammatory effects might effectively treat CA formation. As renin angiotensin system (RAS) is a major inflammatory cascade and related to various vascular diseases, including aortic aneurysms, the role of angiotensin (Ang) II type 1 receptor might contribute to the progression of CAs. However, in cerebral aneurysmal walls, Ang II type 1 receptor was not up-regulated. In addition, subcutaneously administered Ang II type 1 receptor blocker did not inhibit CA formation, nor inflammation in cerebral aneurysmal walls in rat models at a sub-suppressor dose. These results indicate that RAS might play a less important role in CA formation compared to aortic anuerysms or other vascular diseases. This suggests that there are different mechanisms between the pathogenesis of cereberal and aortic aneurysms.
\end{abstract}

\section{Introduction}

The renin angiotensin system (RAS) is believed to play a critical role in the pathogenesis of various vascular diseases such as atherosclerosis (1-9). Angiotensin (Ang) II is a main mediator of RAS and acts via its specific receptors, Ang II type 1 receptor (AT1R) or Ang II type 2 receptor (AT2R) (10).

Correspondence to: Dr Masaki Nishimura, Department of Neurosurgery, Kyoto University, Graduate School of Medicine, 54 Kawaharacho, Shogoin, Sakyo-ku, Kyoto 606-8507, Japan E-mail: masakins@kuhp.kyoto-u.ac.jp

Key words: cerebral aneurysm, angiotensin receptor blocker, angiotensin II type 1 receptor, valsartan, animal model
The Ang II-AT1R axis is a critical mediator of RAS signaling to induce an inflammatory cascade in arterial walls through the activation of NF- $\kappa \mathrm{B}$ transcriptional activity $(9,11,12)$, which is a major transcriptional factor related with up-regulation of various inflammatory cytokines and production of reactive oxygen species $(10,13)$. Chronic inflammation in arterial walls is a common pathological feature and mechanism of various arterial diseases.

Aneurysm refers to the lesion with an outward bulging of arterial walls caused by a hemodynamic force. Although aneurysms are formed in various arteries, the aortic and cerebral aneurysms (CA) are the two most important clinical entities. Both aneurysms are life-threatening and common. However, their underlying pathogenesis must differ to an extent. An aortic aneurysm forms at the side wall of the aorta and bases itself on pre-existing atherosclerotic lesions, whereas $\mathrm{CA}$ forms at the bifurcation site of cerebral arteries and has no relation with atherosclerotic changes in arterial walls. RAS is deeply involved in the pathogenesis of abdominal aortic aneurysms (AAA) $(3,14)$. Many studies revealed that Ang II activated the inflammatory cascade and deteriorated the extracellular matrix of arterial walls and formed AAA $(2,7,15)$. Selective AT1R blocker effectively inhibited AAA formation and rupture by suppressing inflammatory responses in the arterial walls (10). In contrast, the relation of RAS with CA formation remains to be elucidated. An immunohistochemical study implied a decrease in activation of RAS in cerebral aneurysmal walls (16), unlike AAA in which RAS was remarkably up-regulated $(3,14)$. Nevertheless, CA is a disease resulting from chronic arterial inflammation mainly through NF- $\mathrm{KB}$ activation by hemodynamic stress like AAA (17). Thus, in this study, we investigated the expression of AT1R and examined the effects of an AT1R blocker (ARB) on CA formation in rat models.

\section{Materials and methods}

Experimental induction of CAs in rats. CAs were induced as previously described (18). After the induction of pentobarbital anesthesia $(50 \mathrm{mg} / \mathrm{kg}$ i.p.), the left common carotid artery and posterior branches of the bilateral renal arteries were ligated at the same time with 10-0 nylon in 7 week-old male 


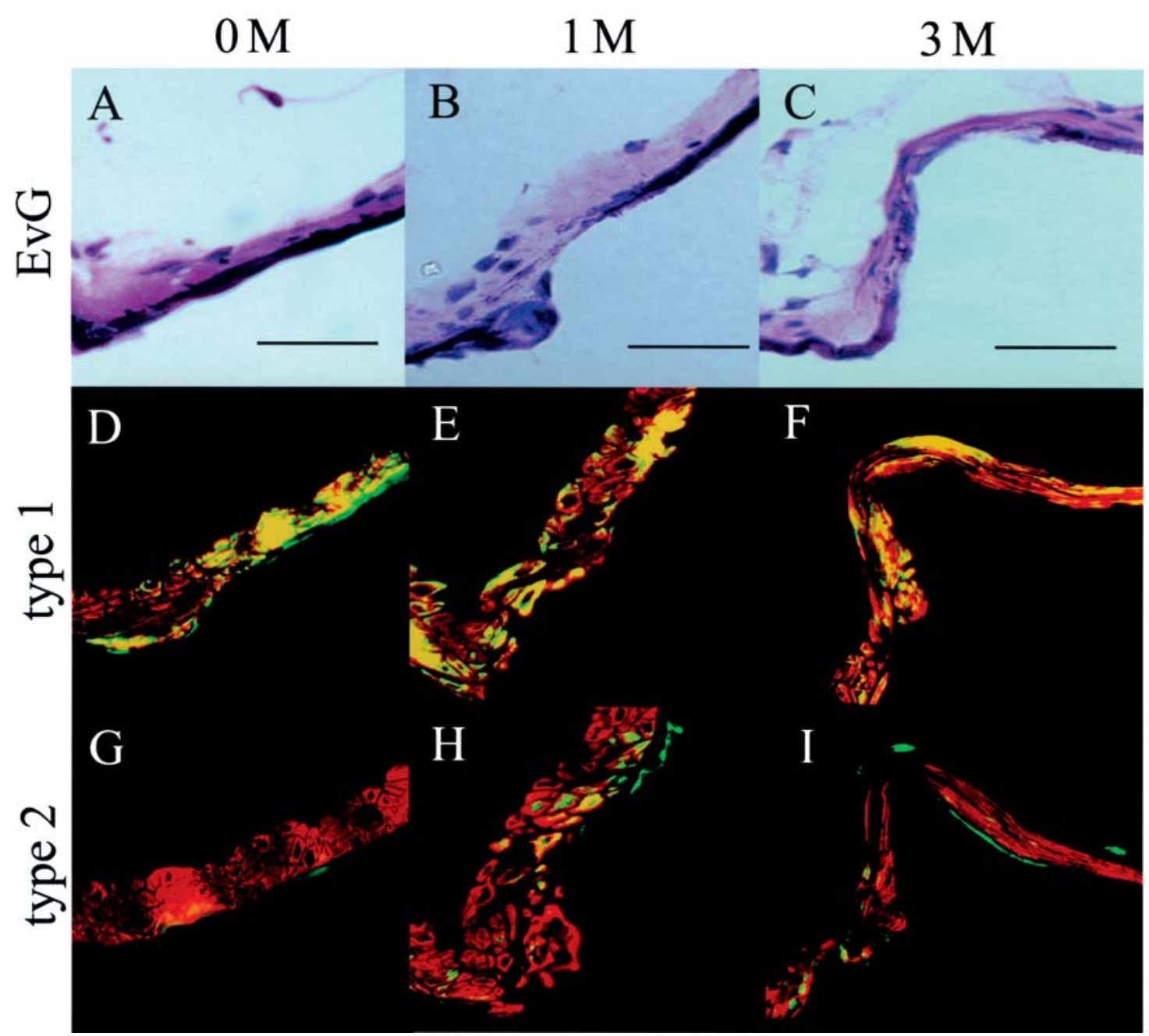

Figure 1. Expression of AT1R and AT2R in cerebral aneurysmal walls of rats. (A-C) Elastica van Gieson staining (EvG) of cerebral aneurysmal walls before $(0 \mathrm{M})$, one month (1 M) or three months (3 M) after aneurysm induction. (D-I) Immunostaining of type 1 (D-F) or type 2 (G-I) receptor (green color: FITC) in cerebral aneurysmal walls. Red color (Cy3) showed smooth muscle $\alpha$-actin staining. Bar, $30 \mu \mathrm{m}$.

Sprague-Dawley rats (Oriental Bioservice, Osaka, Japan). Animals were fed special food containing $8 \%$ sodium chloride and $0.12 \%$ ß-aminopropionitrile (BAPN, Tokyo Chemical, Tokyo, Japan), an inhibitor of lysyl oxidase that catalyzes the cross-linking of collagen and elastin. Blood pressure was measured by the tail-cuff method, keeping rats in small cassettes without anesthesia.

One month after aneurysm induction, the anterior cerebral artery/olfactory artery (ACA/OA) bifurcation was stripped and observed under a light microscope after Elastica van Gieson staining. To evaluate the pathological changes occurring in aneurysmal walls, we analyzed the degeneration of internal elastic lamina (IEL), the thinning of medial smooth muscle cell layer and aneurysm size. IEL was classified into the following three categories: continuous, fragmented and completely disappeared; each category was designated a score: 0,1 and 2 , respectively. The thickness of the media was evaluated by the ratio of minimal thickness in aneurysmal walls to thickness in surrounding normal arterial walls. Aneurysm size was calculated as the mean of the maximal longitudinal diameter and the maximal transverse diameter.

Animal care and experiments complied with Japanese community standards on the care and use of laboratory animals.
Valsartan treatment. Valsartan, N-(1-oxopentyl)-N-[[2'-(1Htetrazol-5-yl)[1,1'-biphenyl]-4-yl]methyl]-L-valine $\left(\mathrm{C}_{24} \mathrm{H}_{29} \mathrm{~N}_{5} \mathrm{O}_{3}\right)$, was generously provided by Novartis Pharmaceuticals (Basel, Switzerland). Valsartan was dissolved in saline containing $1 \%$ methanol and $33 \%$ ethanol. Immediately after aneurysm induction, rats were subjected to continuous subcutaneous injections of valsartan at 1,2 or $5 \mathrm{mg} / \mathrm{kg}$ per day by using Alzet osmotic pump (Alzet, Cupertino, CA) for one month. Valsartan at $1 \mathrm{mg} / \mathrm{kg}$ per day was the same dose used in the previous study (19), in which valsartan did not lower blood pressure but adequately inhibited AT1R activity. In the control group, only the vehicle was continuously injected using the Alzet osmotic pump.

Immunohistochemistry and cell counting. One month $(\mathrm{n}=10)$ after aneurysm induction, all rats were deeply anesthetized and perfused transcardially with $4 \%$ paraformaldehyde. As control, vehicle-injected male Sprague-Dawley rats were sacrificed as described above. The ACA/OA bifurcation was stripped and embedded in OCT compound. Thin sections $(5 \mu \mathrm{m})$ were cut and mounted on silane-coated slides. After blocking with 5\% donkey serum (Jackson ImmunoResearch, Baltimore, MD), primary antibodies were applied and 

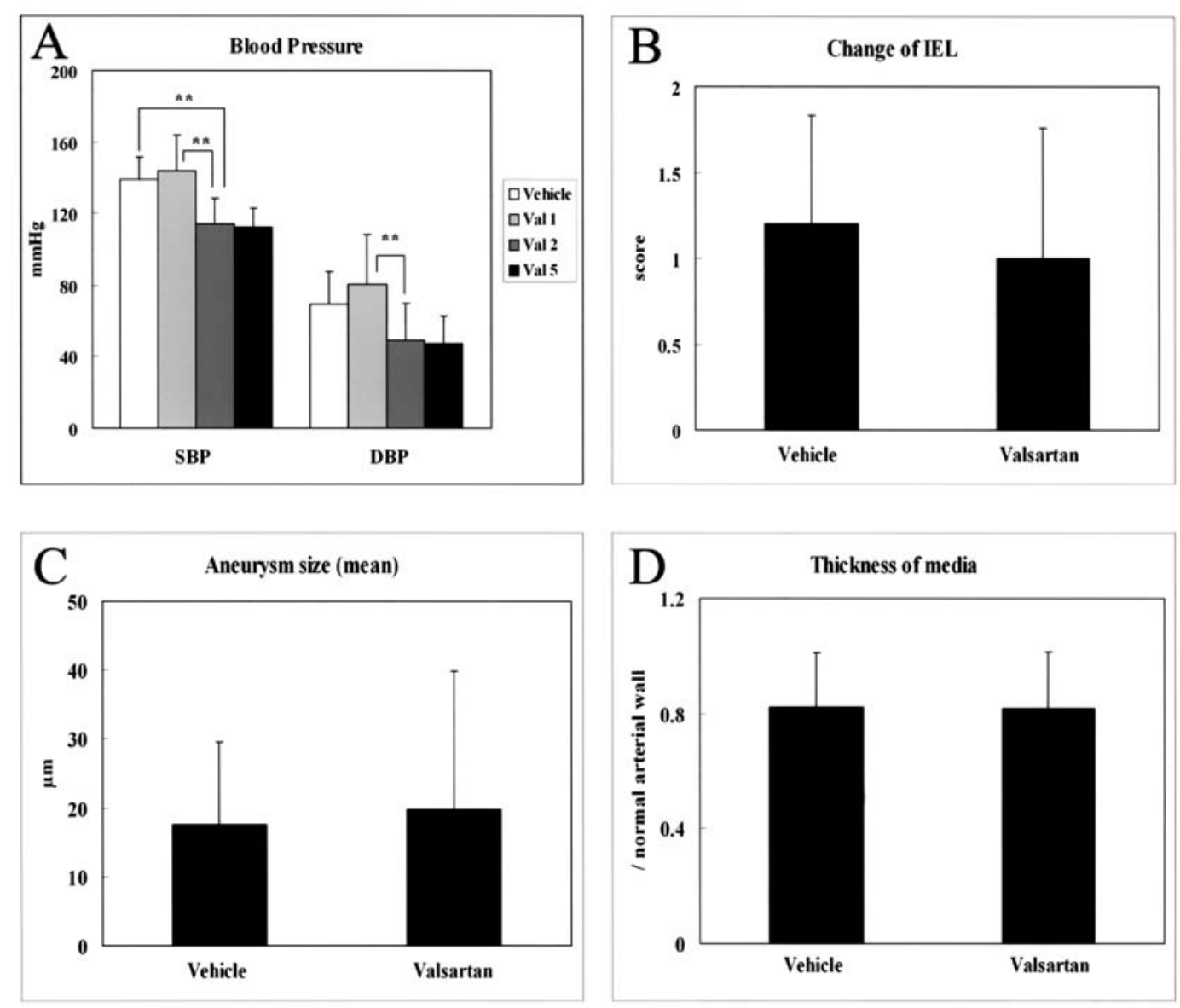

Figure 2. Effect of valsartan on cerebral aneurysm formation in rats. (A) Effect of valsartan on systolic (SBP) and diastolic blood pressure (DBP) by tail cuff method. Val 1: $1 \mathrm{mg} / \mathrm{kg}$; Val 2: $2 \mathrm{mg} / \mathrm{kg}$; Val $5: 5 \mathrm{mg} / \mathrm{kg}$ - per day of valsartan treatment. ${ }^{* *} \mathrm{P}<0.01$. (B-D) Effect of $1 \mathrm{mg} / \mathrm{kg}$ per day of valsartan treatment on change of internal elastic lamina (IEL) (B), aneurysm size (C) and thickness of media (D) of induced aneurysms.

incubated for $1 \mathrm{~h}$ at room temperature followed by incubation with fluorescence labeled secondary antibodies (FITCconjugated donkey anti-rabbit IgG antibody, FITC-conjugated donkey anti-mouse $\mathrm{IgG}$ antibody, Cy3-conjugated donkey anti-mouse $\operatorname{IgG}$ antibody, Cy3-conjugated donkey anti-rabbit $\mathrm{IgG}$ antibody, Cy3-conjugated donkey anti-goat $\mathrm{IgG}$ antibody (Jackson ImmunoResearch)) for $1 \mathrm{~h}$ at room temperature. Then the slides were covered with Permafluor (Immunotec, Marseille, France) and excited for fluorescence by illumination through a fluorescence microscope system (BX51N-34-FL-1, Olympus, Tokyo, Japan).

Primary antibodies used in this study are listed below: rabbit polyclonal anti-monocyte chemoattractant protein (MCP-1) antibody (Santa Cruz, Santa Cruz, CA), mouse monoclonal anti-smooth muscle $\alpha$-actin antibody (Lab Vision, Fermont, CA), goat polyclonal anti-CD68 antibody (Santa Cruz), mouse monoclonal anti-NF- $\mathrm{BB}$ p65 subunit antibody which recognizes only DNA-binding form (Chemicon, Temecula, CA), rabbit polyclonal anti-matrix metalloproteinase (MMP)-2 antibody (Santa Cruz), goat polyclonal anti-MMP-9 antibody (Santa Cruz), rabbit polyclonal anti-AT1R antibody (Santa Cruz), and rabbit polyclonal anti-AT2R antibody (Santa Cruz).

In order to quantify macrophage accumulation in aneurysmal walls, the number of CD68-positive cells was counted in a $10000 \mu \mathrm{m}^{2}$ area around the aneurysm dome in rats.
Gelatin zymography. Total protein from the whole Willis ring was purified by Bio-Plex Cell Lysis Kit (Bio-Rad, Hercules, CA) according to the manufacturer's directions. Protein $(100 \mu \mathrm{g})$ was used in one experiment. Gelatin zymography was performed using Gelatin Zymo-Electrophoresis Kit (Primary cell, Sapporo, Japan) according to the manufacturer's directions. As a marker, recombinant MMP-2 and -9 proteins were used.

RNA isolation and reverse transcription. One month after aneurysm induction, rats were deeply anesthetized and perfused transcardially with $4 \%$ paraformaldehyde. Total RNA from whole Willis ring was isolated using RNeasy Fibrous Tissue Mini Kit (Qiagen, Hilden, Germany). Extraction was performed according to the manufacturer's directions. Total RNA was converted into cDNA using Sensiscript reverse transcriptase (Qiagen).

Quantitative PCR. Constructs for MMP-2 and -9, MCP-1 and $\beta$-actin were produced by Topo Ta Cloning Kit (Invitrogen, Carlsbad, CA) from cDNA according to the manufacturer's directions. Quantitative (real-time) PCR was performed using QuantiTect SYBR Green PCR Kit (Qiagen) and LightCycler Quick System 330 (Roche Diagnostics, Basel, Switzerland). ß-actin was used as an internal control.

The primer sets used were: forward 5'-ctgataacctgga tgcagtcgt-3', reverse 5'-ccagccagtccgatttga-3' for MMP-2, 
forward 5'-ttcaaggacggtcggtatt-3', reverse 5'-ctctgagcc tagacccaactta-3' for MMP-9, forward 5'-cctccaccact atgcaggtctc-3', reverse 5'-gcacgtggatgctacaggc-3' for MCP-1, forward 5'-aagtccetcaccctccaaag-3', reverse 5'-aagcaa tgctgtcaccttccc- $3^{\prime}$ for $\beta$-actin. The conditions for quantitative PCR reactions were: 40 cycles of $95^{\circ} \mathrm{C}(10 \mathrm{sec})$ for the denaturation, $53^{\circ} \mathrm{C}(10 \mathrm{sec})$ for the annealing, and $72^{\circ} \mathrm{C}(10 \mathrm{sec})$ for the extension. The second derivate maximum method was used for crossing point determination, using LightCycler Software 3.3 (Roche Diagnostics). mRNA expression of each gene was calculated as a ratio to $B$-actin. Finally, mRNA expression of the valsartan-treated group was shown as a ratio to that of the vehicle-treated group. Six independent samples were examined in one experiment.

Statistical analysis. Data (mean \pm SD) were analyzed using the Mann-Whitney $U$ test for a two-group comparison and Kruskal-Wallis one-way ANOVA on ranks followed by the Fisher's test for multiple comparison. Differences were considered statistically significant at $\mathrm{P}<0.05$.

\section{Results}

Expression of AT1R and AT2R in cerebral aneurysmal walls of rats. In cerebral aneurysmal walls of rats, AT1R was diffusely expressed in arterial walls as assessed by immunohistochemistry $(n=5)$. The expression pattern was not significantly changed during CA formation (Fig. 1D-F). AT2R was also expressed in cerebral aneurysmal walls at a lesser extent than AT1R, and was not altered during CA formation (Fig. 1G-I).

Effects of ARB on CA. Valsartan at $1 \mathrm{mg} / \mathrm{kg}$ per day did not decrease systemic blood pressure compared with vehicle treatment at one month after aneurysm induction [vehicle treatment: systolic blood pressure (SBP) $138.9 \pm 12.5 \mathrm{mmHg}$, diastolic blood pressure (DBP) $69.2 \pm 18.6 \mathrm{mmHg}, \mathrm{n}=11$; valsartan treatment: SBP $143.8 \pm 19.9 \mathrm{mmHg}$, DBP $80.3 \pm 27.9 \mathrm{mmHg}, \mathrm{n}=12$ ] (Fig. 2A). Valsartan at 2 or $5 \mathrm{mg} / \mathrm{kg}$ per day significantly decreased both SBP and DBP compared with $1 \mathrm{mg} / \mathrm{kg}$ treated group $(2 \mathrm{mg} / \mathrm{kg}$ per day of valsartan treatment: SBP $114.0 \pm 14.3 \mathrm{mmHg}$, DBP $48.8 \pm 21.1 \mathrm{mmHg}$, $\mathrm{n}=6 ; 5 \mathrm{mg} / \mathrm{kg}$ per day of valsartan treatment: SBP 112.4 $\pm 10.4 \mathrm{mmHg}$, DBP $47.4 \pm 15.1 \mathrm{mmHg}, \mathrm{n}=7 ;$ SBP: $1 \mathrm{mg} / \mathrm{kg}$ vs. $2 \mathrm{mg} / \mathrm{kg}, \mathrm{P}<0.01$; DBP: $1 \mathrm{mg} / \mathrm{kg}$ vs. $2 \mathrm{mg} / \mathrm{kg}, \mathrm{P}<0.01)$. Therefore, to study the effects of ARB on CA formation, we chose $1 \mathrm{mg} / \mathrm{kg}$ dose to avoid the hemodynamic effects. Unexpectedly, valsartan at $1 \mathrm{mg} / \mathrm{kg}$ per day for one month just after aneurysm induction did not change IEL disruption by scoring criteria (vehicle-treated group: $1.2 \pm 0.6, \mathrm{n}=10$; valsartan-treated group: $1.0 \pm 0.76, \mathrm{n}=10$ ) (Fig. $2 \mathrm{~B}$ ). Size and medial thickness of induced aneurysms were also not significantly different between the vehicle- and valsartantreated group (aneurysm size: vehicle-treated group: $17.6 \pm 12.0 \mu \mathrm{m}, \mathrm{n}=10$ valsartan-treated group: $19.8 \pm 20.0 \mu \mathrm{m}$, $\mathrm{n}=10$; medial thickness: vehicle-treated group: $0.82 \pm 0.19$, $\mathrm{n}=10$; valsartan-treated groups: $0.82 \pm 0.20, \mathrm{n}=10$ ) (Fig. $2 \mathrm{C}$ and D). Macrophages were the main inflammatory cells in cerebral aneurysmal walls. The number of macrophages infiltrated into cerebral aneurysmal walls one month after
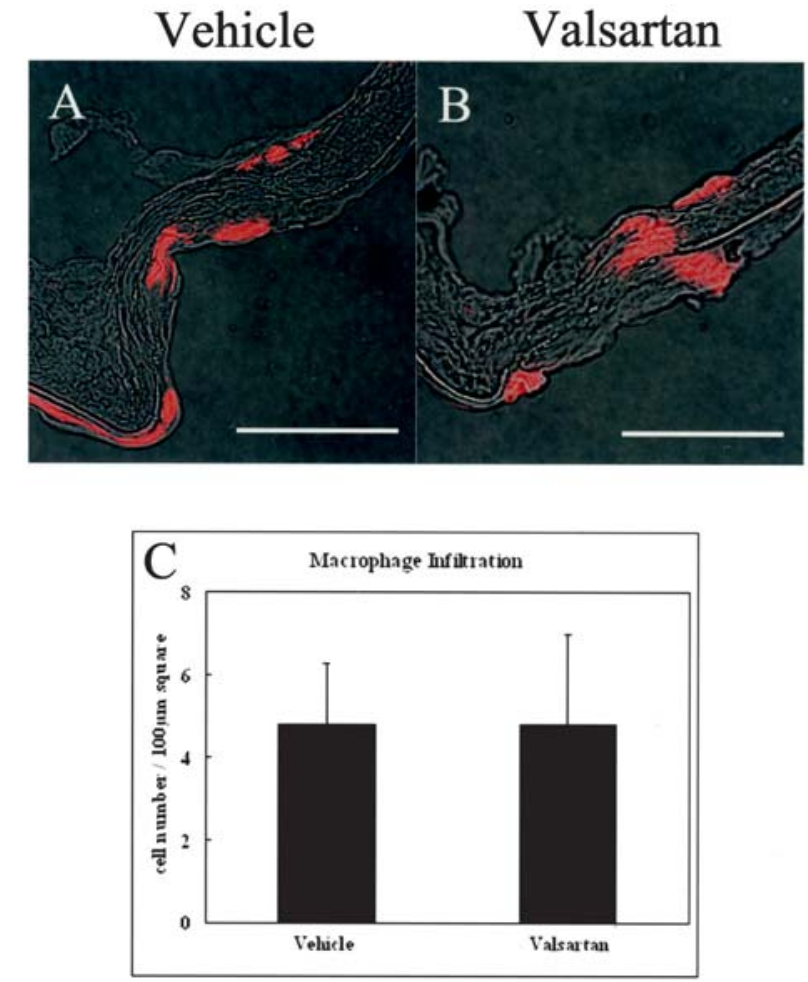

Figure 3. Macrophage infiltration into cerebral aneurysmal walls. (A and B) Immunostaining of CD68-positive cells (macrophages) in cerebral aneurysmal walls of rats with vehicle (A) or valsartan treatment (B). Bar: $30 \mu \mathrm{m}$. (C) Number of macrophage infiltration into cerebral aneurysmal walls per $100 \mu \mathrm{m}$ square around aneurysm.

aneurysm induction was not significantly different between the vehicle- and valsartan-treated groups (vehicle-treated group: $4.8 \pm 1.5$ cells $/ 10000 \mu \mathrm{m}^{2}, \mathrm{n}=5$; valsartan-treated group: $4.8 \pm 2.2$ cells/10000 $\mu \mathrm{m}^{2}, \mathrm{n}=5$ ) (Fig. 3). Similarly, there were no significant statistical differences in MCP-1, MMP-2 and -9 mRNA expression by quantitative real-time PCR analysis between vehicle and valsartan treated groups (Fig. 4). Immunohistochemistry also did not reveal a significant change in expression of molecules in the cerebral aneurysmal walls (Fig. 5A-J). Proteolytic activities of MMP-2 and -9 by gelatine zymography were also not different between vehicleand valsartan-treated groups (Fig. 5K).

\section{Discussion}

Subarachnoid hemorrhage is a devastating disease with a 30day mortality rate of $30 \%$ and mild-to-severe morbidity rate of $45 \%(20,21)$. The majority of survivors from subarachnoid hemorrhage are unable to participate in society as they did before even if they recover because of latent cognitive impairment (22). The main cause of subarachnoid hemorrhage is the rupture of a pre-existing CA. CA is a common disease with a frequency of 1 to $5 \%$ in large autopsy series (23). CA is often found before rupture by diagnostic techniques such as magnetic resonance angiography (MRA). Only a small number of patients with an unruptured CA undergo surgical procedures such as microneurosurgical clipping or endovascular coiling. However, there is a substantial risk of complications. Most patients with unruptured CAs are 

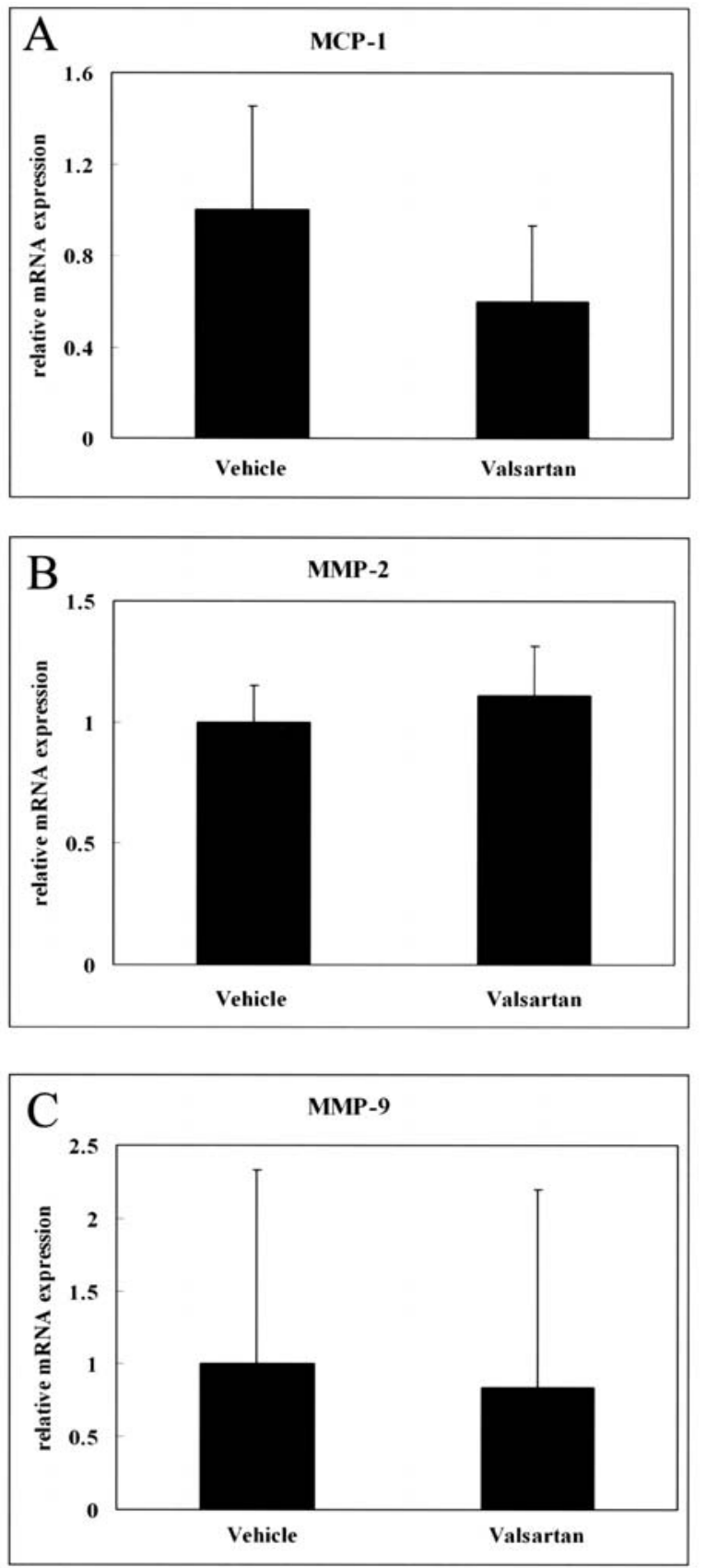

Figure 4. Effect of valsartan on MCP-1, MMP-2 and MMP-9 mRNA expression. (A-C) Result of quantitative real-time PCR analysis of MCP-1 (A), MMP-2 (B) and MMP-9 (C) with vehicle or valsartan treatment $(n=6)$.

followed up under sequential radiological evaluation. Nevertheless, there is no oral medical treatment against unruptured CAs due to the limited knowledge regarding the mechanisms of CA formation.

We have clarified some of the underlying mechanisms of CA formation by previously establishing an animal model of CA (24). Pathologically, CA is characterized by excessive degradation of extracellular matrix in arterial walls. NF- $\mathrm{B}$ was activated by hemodynamic stress in endothelial cells of cerebral arterial bifurcation and might play a crucial role in CA formation by transcriptionally inducing various inflammatory genes (17). NF-кB up-regulated MCP-1 expression in the endothelial cell layer, and activated macrophage infiltration

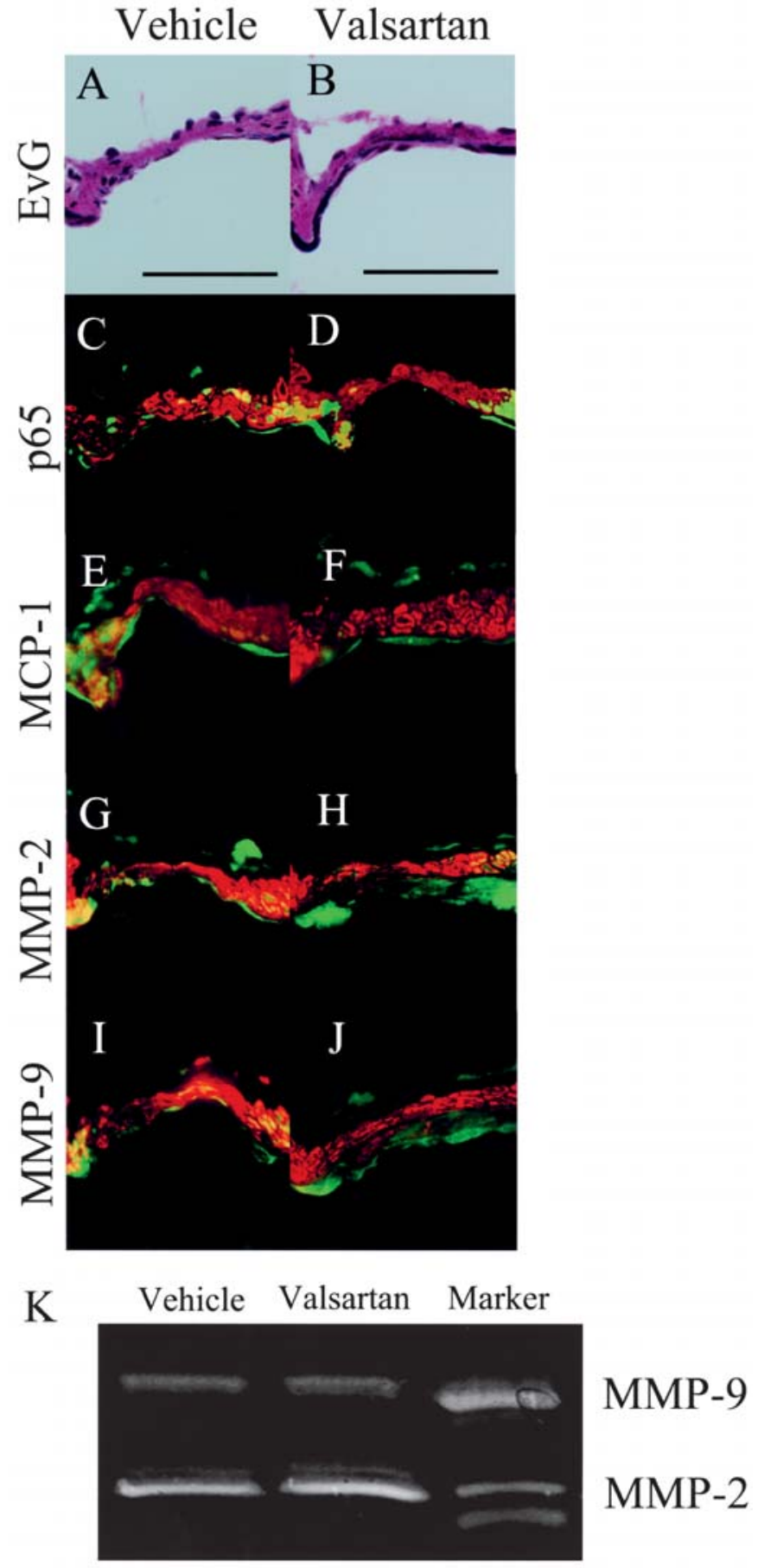

Figure 5. Immunostaining of NF-кB, MCP-1, MMP-2 and MMP-9 in cerebral aneurysmal walls and zymography of MMP-2 and MMP-9 activities. Immunostaining of DNA binding form of NF-kB p65 subunit (C and D), MCP-1 (E and F), MMP-2 (G and H) and MMP-9 (I and J) in cerebral aneurysmal walls of rats with vehicle $(\mathrm{C}, \mathrm{E}, \mathrm{G}, \mathrm{I})$ or valsartan treatment $(\mathrm{D}, \mathrm{F}, \mathrm{H}, \mathrm{J})$. (A and B) Elastica van Gieson staining (EvG) of serial section as C (A) or D (B). Bar: $30 \mu \mathrm{m}$. (K) Representative image of gelatine zymography from five independent experiments.

into arterial walls. Infiltrated macrophages expressed various tissue destructive proteinases or inflammation related molecules such as MMPs (25).

AAA is another aneurysm which people commonly suffer. AAA is also a life-threatening disease similar to CA. The detailed mechanisms of AAA formation are well-known. 
In the aorta, atherosclerotic change, mainly by oxidative LDL, first occurs and macrophages infiltrate into arterial walls. Chronic inflammation in the aorta by infiltrated macrophages causes excessive degradative change in arterial walls and decreases arterial stiffness, leading to the development of AAA $(1,2)$. AAA and CA are similar clinical entities, in part because both aneurysms are a result of chronic inflammation in arterial walls. However, different underlying mechanisms between AAA and CA must be recognized, since AAA is a result of atherosclerotic changes of arterial walls and $\mathrm{CA}$ is not related with atherosclerosis. In pathological studies, CA is not accompanied by atherosclerosis (26). Furthermore, in ApoE knockout mice, which presented marked hypercholesterolemia, CA formation was not changed, indicating that hypercholesterolemia, a main risk factor of atherosclerosis, might not be responsible for CA formation (27). MMP-9 is a proteinase with both collagenase and elastase activity, and plays a critical role in both CA (25) and AAA formation $(28,29)$. MMP-2 is another proteinase with both collagenase and elastase activity. Interestingly, in CA, MMP-2 plays a critical role in aneurysm formation (25), while in AAA it does not. The different phenomena would suggest the different pathogenesis between CA and AAA.

RAS plays an important role in the regulation of systemic blood pressure (10). Ang II is a final and most important mediator of this system. Although Ang II binds its receptors, AT1R and AT2R, AT1R mediates the main inflammatory signaling of Ang II such as NF- $\mathrm{KB}$ activation $(9,11,12)$. Thus, the selective blockade of AT1R is a drug target against hypertension and various inflammation-related vascular diseases such as atherosclerosis. Indeed, AT1R blockers have potent anti-inflammatory effects, in addition to their blood pressure lowering effect. Numerous studies have shown the preferable effects of AT1R blockers on various inflammatory diseases such as atherosclerosis (4), AAA $(19,30)$ and diabetic nephropathy (12).

In the present study, we employed an AT1R blocker, valsartan $(31,32)$, since valsartan is widely used. Previous studies demonstrated that in AAA, AT1R was markedly upregulated in aneurysmal walls and an AT1R blocker effectively inhibited AAA formation and rupture by suppressing the inflammatory cascade in arterial walls $(2,3,14,19,30)$. However, we demonstrated that in the cerebral aneurysmal walls of rats, AT1R was not up-regulated. Similarly, the previous report also demonstrated down-regulation of AT1R in humans (16). These results might indicate that local RAS would be suppressed or at least unchanged in cerebral aneurysmal walls unlike AAA. Indeed, an AT1R blocker failed to inhibit CA formation in rats at the dose which did not influence systemic blood pressure. Consistently, activation of NF-кB, MMP-2 and MCP-1 in cerebral aneurysmal walls was not inhibited by an AT1R blocker. Thus, unexpectedly, an AT1R blocker failed to show anti-inflammatory effects at a dose which did not affect systemic blood pressure in cerebral aneurysmal walls.

Overall, the present study demonstrated the different effects of the role RAS plays for both AAA and CA, providing new insight into the pathogenesis of CA formation. Further studies are necessary to clarify the detailed mechanisms of CA formation to prevent CA rupture.

\section{Acknowledgements}

This work was supported by a Grant-in-Aid for Scientific Research (no. 17390399) from the Ministry of Education, Science and Culture of Japan. We thank Novartis Pharmaceuticals for kindly providing the valsartan.

\section{References}

1. Ayabe N, Babaev VR, Tang Y, Tanizawa T, Fogo AB, Linton MF, Ichikawa I, Fazio $\mathrm{S}$ and Kon V: Transiently heightened angiotensin II has distinct effects on atherosclerosis and aneurysm formation in hyperlipidemic mice. Atherosclerosis 184: 312-321, 2006.

2. Daugherty A, Manning MW and Cassis LA: Angiotensin II promotes atherosclerotic lesions and aneurysms in apolipoprotein E-deficient mice. J Clin Invest 105: 1605-1612, 2000.

3. Daugherty A, Rateri DL and Cassis LA: Role of the reninangiotensin system in the development of abdominal aortic aneurysms in animals and humans. Ann NY Acad Sci 1085: 8291, 2006.

4. Iwai M, Chen R, Li Z, Shiuchi T, Suzuki J, Ide A, Tsuda M, Okumura M, Min LJ, Mogi M and Horiuchi M: Deletion of angiotensin II type 2 receptor exaggerated atherosclerosis in apolipoprotein E-null mice. Circulation 112: 1636-1643, 2005.

5. Liao S, Miralles M, Kelley BJ, Curci JA, Borhani M and Thompson RW: Suppression of experimental abdominal aortic aneurysms in the rat by treatment with angiotensin-converting enzyme inhibitors. J Vasc Surg 33: 1057-1064, 2001.

6. Nagai N, Oike Y, Izumi-Nagai K, Urano T, Kubota Y, Noda K, Ozawa $Y$, Inoue $M$, Tsubota $K$, Suda $T$ and Ishida $S$ : Angiotensin II type 1 receptor-mediated inflammation is required for choroidal neovascularization. Arterioscler Thromb Vasc Biol 26: 2252-2259, 2006.

7. Nishimoto M, Takai S, Fukumoto H, Tsunemi K, Yuda A, Sawada Y, Yamada M, Jin D, Sakaguchi M, Nishimoto Y, Sasaki S and Miyazaki M: Increased local angiotensin II formation in aneurysmal aorta. Life Sci 71: 2195-2205, 2002.

8. Wu L, Iwai M, Nakagami H, Li Z, Chen R, Suzuki J, Akishita M, de Gasparo M and Horiuchi M: Roles of angiotensin II type 2 receptor stimulation associated with selective angiotensin II type 1 receptor blockade with valsartan in the improvement of inflammation-induced vascular injury. Circulation 104: 2716-2721, 2001.

9. Yoshiyama M, Omura T, Takeuchi K, Kim S, Shimada K, Yamagishi $\mathrm{H}$, Teragaki M, Akioka K, Iwao $\mathrm{H}$ and Yoshikawa J: Angiotensin blockade inhibits increased JNKs, AP-1 and NF-kB DNA-binding activities in myocardial infarcted rats. J Mol Cell Cardiol 33: 799-810, 2001.

10. El Bekay R, Alvarez M, Monteseirin J, Alba G, Chacon P, Vega A, Martin-Nieto J, Jimenez J, Pintado E, Bedoya FJ and Sobrino F: Oxidative stress is a critical mediator of the angiotensin II signal in human neutrophils: involvement of mitogen-activated protein kinase, calcineurin, and the transcription factor NF-кB. Blood 102: 662-671, 2003.

11. Nagai N, Izumi-Nagai K, Oike Y, Koto T, Satofuka S, Ozawa Y, Yamashiro K, Inoue M, Tsubota K, Umezawa K and Ishida S: Suppression of diabetes-induced retinal inflammation by blocking the angiotensin II type 1 receptor or its downstream nuclear factor-kappaB pathway. Invest Ophthalmol Vis Sci 48: 4342-4350, 2007

12. Lee FT, Cao Z, Long DM, Panagiotopoulos S, Jerums G, Cooper ME and Forbes JM: Interactions between angiotensin II and NF- $\mathrm{kB}$-dependent pathways in modulating macrophage infiltration in experimental diabetic nephropathy. J Am Soc Nephrol 15: 2139-2151, 2004.

13. Pueyo ME, Arnal JF, Rami J and Michel JB: Angiotensin II stimulates the production of $\mathrm{NO}$ and peroxynitrite in endothelial cells. Am J Physiol 274: C214-C220, 1998.

14. Daugherty A and Cassis L: Angiotensin II and abdominal aortic aneurysms. Curr Hypertens Rep 6: 442-446, 2004.

15. Nishijo N, Sugiyama F, Kimoto K, Taniguchi K, Murakami K, Suzuki S, Fukamizu A and Yagami K: Salt-sensitive aortic aneurysm and rupture in hypertensive transgenic mice that overproduce angiotensin II. Lab Invest 78: 1059-1066, 1998.

16. Ohkuma H, Suzuki S, Fujita S and Nakamura W: Role of a decreased expression of the local renin-angiotensin system in the etiology of cerebral aneurysms. Circulation 108: 785-787, 2003. 
17. Aoki T, Kataoka H, Shimamura M, Nakagami H, Wakayama K, Moriwaki T, Ishibashi R, Nozaki K, Morishita R and Hashimoto N: NF- $\mathrm{kB}$ is a key mediator of cerebral aneurysm formation. Circulation 116: 2830-2840, 2007.

18. Nagata I, Handa H, Hashimoto $\mathrm{N}$ and Hazama F: Experimentally induced cerebral aneurysms in rats: Part VI. Hypertension. Surg Neurol 14: 477-479, 1980.

19. Fujiwara Y, Shiraya S, Miyake T, Yamakawa S, Aoki M, Makino H, Nishimura M and Morishita R: Inhibition of experimental aortic abdominal aneurysm in a rat model by angiotensin receptor blocker, valsartan. Int $\mathrm{J}$ Mol Med 22: 703$708,2008$.

20. van Gijn J, Kerr RS and Rinkel GJ: Subarachnoid hemorrhage. Lancet 369: 306-318, 2007.

21. Feigin VL and Findlay M: Advances in subarachnoid hemorrhage. Stroke 37: 305-308, 2006

22. Wermer MJ, Kool H, Albrecht KW and Rinkel GJ: Subarachnoid hemorrhage treated with clipping: long-term effects on employment, relationships, personality, and mood. Neurosurgery 60: 91-97, 2007.

23. Wiebers DO, Whisnant JP, Huston J III, Meissner I, Brown RD Jr, Piepgras DG, Forbes GS, Thielen K, Nichols D, O'Fallon WM Peacock J, Jaeger L, Kassell NF, Kongable-Beckman GL and Torner JC: Unruptured intracranial aneurysms: natural history, clinical outcome, and risks of surgical and endovascular treatment. Lancet 362: 103-110, 2003.

24. Hashimoto N, Handa H and Hazama F: Experimentally induced cerebral aneurysms in rats. Surg Neurol 10: 3-8, 1978.

25. Aoki T, Kataoka H, Morimoto M, Nozaki K and Hashimoto N: Macrophage-derived matrix metalloproteinase-2 and -9 promote the progression of cerebral aneurysms in rats. Stroke 38: 162$169,2007$.
26. Hashimoto N, Handa $\mathrm{H}$ and Hazama F: Experimentally induced cerebral aneurysms in rats: Part III. Pathology. Surg Neurol 11: 299-304, 1979.

27. Aoki T, Moriwaki T, Takagi Y, Kataoka H, Nozaki K and Hashimoto N: The efficacy of apolipoprotein E deficiency in experimental cerebral aneurysm formation. Int $\mathrm{J}$ Mol Med 21: 453-459, 2008.

28. Wilson WR, Anderton M, Schwalbe EC, Jones JL, Furness PN, Bell PR and Thompson MM: Matrix metalloproteinase-8 and -9 are increased at the site of abdominal aortic aneurysm rupture. Circulation 113: 438-445, 2006.

29. Jones JA, Barbour JR, Lowry AS, Bouges S, Beck C, McClister DM Jr, Mukherjee R and Ikonomidis JS: Spatiotemporal expression and localization of matrix metalloproteinase-9 in a murine model of thoracic aortic aneurysm. J Vasc Surg 44: 1314-1321, 2006.

30. Daugherty A, Manning MW and Cassis LA: Antagonism of AT2 receptors augments angiotensin II-induced abdominal aortic aneurysms and atherosclerosis. Br J Pharmacol 134: 865-870, 2001.

31. Yamamoto S, Hayashi N, Kometani M, Nakao K and Inukai T: Pharmacological profile of valsartan, a non-peptide angiotensin II type 1 receptor antagonist. 1st communication: antihypertensive effects of valsartan in hypertensive models. Arzneimittelforschung 47: 604-612, 1997.

32. Thurmann PA: Valsartan: a novel angiotensin type 1 receptor antagonist. Expert Opin Pharmacother 1: 337-350, 2000. 